\title{
Correction to: Developmentally anomalous cerebellar encephalocele arising within the cerebellopontine angle and extending into the adjacent skull base in a pediatric patient
}

\author{
Forrest A. Hamrick ${ }^{1} \cdot$ Michael Karsy ${ }^{1} \cdot$ Carol S. Bruggers ${ }^{2,3}$ - Angelica R. Putnam ${ }^{2,4}$ - Gary L. Hedlund ${ }^{2,5}$. \\ Samuel H. Cheshier ${ }^{1,2}$ (1)
}

Published online: 4 November 2021

(c) Springer-Verlag GmbH Germany, part of Springer Nature 2021

\section{Child's Nervous System (2021) 37:2943-2947 https://doi.org/10.1007/s00381-020-05020-8}

The article "Developmentally anomalous cerebellar encephalocele arising within the cerebellopontine angle and extending into the adjacent skull base in a pediatric patient", written by Hamrick, F.A., Karsy, M., Bruggers, C.S. et al. was originally published online on 10 February 2021 with Open Access under a Creative Commons Attribution 4.0 International License.

After publication in volume 37, issue 9, page 2943-2947, the publisher determined the Open Access designation had been applied erroneously. Therefore, the copyright of the article has been changed on 14 October 2021 to $\odot$ SpringerVerlag GmbH Germany, part of Springer Nature 2021 with all rights reserved.

Publisher's Note Springer Nature remains neutral with regard to jurisdictional claims in published maps and institutional affiliations.

The original article can be found online at https://doi.org/10.1007/ s00381-020-05020-8.

Samuel H. Cheshier

neuropub@hsc.utah.edu

1 Division of Pediatric Neurosurgery, Department of Neurosurgery, University of Utah, 100 N. Mario Capecchi Drive, Salt Lake City, UT 84113, USA

2 Primary Children's Hospital, University of Utah, Salt Lake City, UT, USA

3 Division of Neuro-Oncology, Department of Pediatrics, University of Utah, Salt Lake City, UT, USA

4 Department of Pathology, University of Utah, Salt Lake City, UT, USA

5 Department of Medical Imaging, Primary Children's Hospital, University of Utah, Salt Lake City, UT, USA 